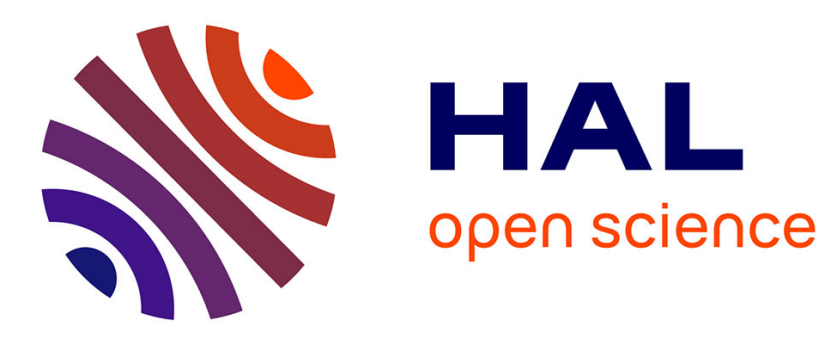

\title{
In situ detection of aerosol layers in the middle stratosphere
}

\author{
Jean-Baptiste Renard, Gwenaël Berthet, Verónica Salazar, Valéry Catoire, \\ Michel Tagger, Bertrand Gaubicher, Claude Robert
}

\section{- To cite this version:}

Jean-Baptiste Renard, Gwenaël Berthet, Verónica Salazar, Valéry Catoire, Michel Tagger, et al.. In situ detection of aerosol layers in the middle stratosphere. Geophysical Research Letters, 2010, 20, 37, L20803 (5 p.). 10.1029/2010GL044307 . insu-01391516

\section{HAL Id: insu-01391516 https://hal-insu.archives-ouvertes.fr/insu-01391516}

Submitted on 3 Nov 2016

HAL is a multi-disciplinary open access archive for the deposit and dissemination of scientific research documents, whether they are published or not. The documents may come from teaching and research institutions in France or abroad, or from public or private research centers.
L'archive ouverte pluridisciplinaire HAL, est destinée au dépôt et à la diffusion de documents scientifiques de niveau recherche, publiés ou non, émanant des établissements d'enseignement et de recherche français ou étrangers, des laboratoires publics ou privés. 


\title{
In situ detection of aerosol layers in the middle stratosphere
}

\author{
Jean-Baptiste Renard, ${ }^{1}$ Gwenaël Berthet, ${ }^{1}$ Verónica Salazar, ${ }^{1}$ Valery Catoire, ${ }^{1}$ \\ Michel Tagger, ${ }^{1}$ Bertrand Gaubicher, ${ }^{1}$ and Claude Robert ${ }^{1}$ \\ Received 11 June 2010; revised 17 August 2010; accepted 27 August 2010; published 21 October 2010.
}

[1] We present here 14 new flights of the aerosol counter STAC, performed in the 2008-2010 period under 3 different geophysical conditions: equator, summer Arctic, and spring Arctic. Measurements were conducted during the balloon ascent, at float altitude, and during the balloon descent. The float altitude was between 14 and $2 \mathrm{hPa}(29-42 \mathrm{~km})$, depending on the flights. Aerosol enhancements were detected for altitude levels above $40 \mathrm{hPa}$, with a stronger variability above $20 \mathrm{hPa}$. Two of them could be attributed to the fortuitous detection of meteoric debris. Thin layers of strong local enhancements of submicronic aerosols were detected during the other flights. Using simultaneous in situ measurements of the $\mathrm{N}_{2} \mathrm{O}$ tracers by the infra-red SPIRALE balloon-borne spectrometer, it can be concluded that the occurrence of these enhancements is not directly linked to the variability of air mass origins. A process involving atmospheric electric field is proposed to tentatively explain the aerosol containment. Citation: Renard, J.-B., G. Berthet, V. Salazar, V. Catoire, M. Tagger, B. Gaubicher, and C. Robert (2010), In situ detection of aerosol layers in the middle stratosphere, Geophys. Res. Lett., 37, L20803, doi:10.1029/2010GL044307.

\section{Introduction}

[2] The interests of studying stratospheric aerosols are numerous, all of them of great importance. Aerosols affect global climate forcing through direct and indirect radiative effects [Lary et al., 1999]. In the stratosphere, aerosols influence ozone chemistry, especially the ozone depletion though polar stratospheric clouds formation [Solomon, 1999]. Studies of stratospheric aerosols have contributed to better characterize their general distribution and the content variability during volcanic and post volcanic conditions [e.g., Hitchman et al., 1994; Deshler et al., 2003; Bingen et al., 2003; Hofmann et al., 2009].

[3] However stratospheric aerosols are difficult to study, because of their different natures, shapes and sizes. The vertical and horizontal distribution of aerosols in the middle and higher stratosphere, as well as their nature, origin and physical properties, are still poorly documented and not yet totally understood. Aerosols are usually considered to be almost non-existent above $35 \mathrm{~km}$. In fact, their detection in the middle stratosphere is difficult due to their low optical thickness. Fussen et al. [2001] have analyzed the stratospheric aerosol distributions measured by the solar Occultation RAdiometer (ORA) satellite instrument from August 1992 to May 1993, and have shown evidence for efficient transport of particles coming from the Junge layer (around

\footnotetext{
${ }^{1}$ LPC2E, Université d'Orléans, CNRS, Orléans, France.
}

the tropopause) up to $50 \mathrm{~km}$ of altitude. Other examples of detection of aerosols in the middle and upper stratosphere can be found in the literature. Hervig et al. [2009] have made the first satellite observations of meteoric smoke particles from 35 to $85 \mathrm{~km}$ altitude, using the Solar Occultation For Ice Experiment (SOFIE). Klekociuk et al. [2005] have observed one enhancement of aerosol content around $30 \mathrm{~km}$ using a lidar, which was well identified as coming from the disintegration of a large meteoroid of a few meters of diameter on 3 September 2004 over Antarctica. The detected layer had a vertical extent of several hundred meters.

[4] The presence of aerosols between 25 and $30 \mathrm{~km}$ in the free-volcanic aerosol period was also detected using the balloon-borne aerosol counter STAC and the UV-visible spectrometer SALOMON [Renard et al., 2005]. In a further study carried out with these instruments, along with the balloon-borne radiometer MicroRADIBAL, and the GOMOS/ Envisat satellite instrument, Renard et al. [2008] have concluded on the presence of significant amounts of aerosols above $30 \mathrm{~km}$, and suggest the existence of a layer of soot particles between 22 and $30 \mathrm{~km}$.

[5] In the present paper, we study the content of stratospheric aerosols in the stratosphere up to an altitude of $42 \mathrm{~km}$, using new in situ measurements obtained by an improved version of the balloon-borne aerosol counter STAC. Such an instrument provides one-shot measurements at given locations and times, with high accuracies in counting and in vertical resolution. It is well adapted to tentatively detect short-time variability of the aerosol content.

\section{STAC Aerosol Counter}

[6] STAC (Stratospheric and Tropospheric Aerosol Counter) is an aerosol counter dedicated to the measurements of aerosols concentrations in various size classes [Ovarlez and Ovarlez, 1995; Renard et al., 2005, 2008]. The measurements of light scattered by aerosols that cross the laser beam are performed at a scattering angle of $70^{\circ}$. Since the publication of papers mentioned above, STAC has been improved. Firstly, 14 size classes are now available between 0.30 and $5 \mu \mathrm{m}$ (the 0.30 and 0.35 size classes have been available since 2010), instead of the previous 7 size classes between 0.40 and $2 \mu \mathrm{m}$. Secondly, in-flight calibrations are conducted in order to determine the variations of stray light that can occur from one flight to another (the size classes can slightly differ for all the flights).

[7] Some of the new measurements presented here are performed close to the highest altitude that stratospheric balloons can reach. Tests in a low pressure chamber have been conducted to assess the pumping system in order to check STAC's good operating at such altitudes. By taking into account the pump efficiency, the counting uncertainty is of $60 \%$ for aerosol concentrations lower than 
Table 1. Conditions of the Measurements

\begin{tabular}{lccc}
\hline \multicolumn{1}{c}{ Date } & Time TU & $\begin{array}{c}\text { Launching } \\
\text { Place }\end{array}$ & $\begin{array}{c}\text { Float Altitude } \\
\mathrm{hPa}(\mathrm{km})\end{array}$ \\
\hline 9-10 June 2008 & $23: 20 \rightarrow 06: 20$ & Teresina & $7(34)$ \\
19-20 June 2008 & $21: 20 \rightarrow 01: 00$ & Teresina & $6(35)$ \\
2 August 2009 & $18: 10 \rightarrow 22: 05$ & Kiruna & $12(30)$ \\
7 August 2009 & $01: 40 \rightarrow 06: 25$ & Kiruna & $7(34)$ \\
14 August 2009 & $09: 35 \rightarrow 15: 50$ & Kiruna & $7(34)$ \\
18 August 2009 & $13: 35 \rightarrow 18: 30$ & Kiruna & $12(30)$ \\
24-25 August 2009 & $20: 40 \rightarrow 02: 00$ & Kiruna & $7(34)$ \\
25 August 2009 & $15: 10 \rightarrow 22: 30$ & Kiruna & $5(36)$ \\
26 August 2009 & $19: 15 \rightarrow 23: 35$ & Kiruna & $12(30)$ \\
7-8 September 2009 & $14: 50 \rightarrow 06: 30^{\mathrm{a}}$ & Kiruna & $7(34)$ \\
4 April 2010 & $17: 45 \rightarrow 20: 50$ & Kiruna & $12(30)$ \\
9 April 2010 2010 & $15: 00 \rightarrow 19: 25$ & Kiruna & $6(34)$ \\
25 April 2010 & $15: 00 \rightarrow 15: 25^{\mathrm{b}}$ & Kiruna & $5(35)$ \\
19 May 2010 & $03: 30 \rightarrow 07: 50$ & Kiruna & $2(42)$ \\
\hline
\end{tabular}

\footnotetext{
${ }^{\mathrm{a}}$ Vertical excursion between $7 \mathrm{hPa}(34 \mathrm{~km})$ and $14 \mathrm{hPa}(29 \mathrm{~km})$ during float.

${ }^{\mathrm{b}}$ Measurements conducted only during the descent.
}

$10^{-3} \mathrm{~cm}^{-3} \mu \mathrm{m}^{-1}, 20 \%$ at $10^{-2} \mathrm{~cm}^{-3} \mu \mathrm{m}^{-1}$, and better than $6 \%$ for concentrations higher than $0.1 \mathrm{~cm}^{-3} \mu \mathrm{m}^{-1}$. The background noise of the detector and of the electronics limits the lower size of aerosol that can be detected.

[8] STAC is calibrated in order to provide size distributions of liquid aerosols. For measurements in presence of solid aerosols characterized by a non-negligible imaginary part of the refractive index, the light scattered at $70^{\circ}$ scattering angle is weaker than for liquid particles. The concentration at a given size class can be underestimated, because the contribution of solid aerosols could be attributed to lower size classes, depending on the nature of the particles. In this case, the size distribution becomes inaccurate. Nevertheless, the aerosols counter can be used to determine the total number of aerosols (liquid and solid) that scatter amounts of light above the sensitivity threshold of the detector.

[9] There are 3 copies of STAC, which can be mounted on various gondolas under stratospheric balloons. In particular, STAC can be onboard the SPIRALE gondola. SPIRALE is a tunable diode laser absorption spectrometer [Moreau et al., 2005], providing in situ measurements of tracer species such as $\mathrm{N}_{2} \mathrm{O}$ and $\mathrm{CH}_{4}$. Since STAC and SPIRALE analyze the same air masses, it is possible to investigate the correlation between the aerosol content and the air mass origin.

\section{Conditions of the Measurements}

[10] Measurements are conducted during the balloon ascent, at float altitude which can last from tens of minutes to several hours, during the controlled slow descent, and during the fast descent under parachutes at the end of the flight. The conditions of these measurements allow us to retrieve two vertical profiles several tens of $\mathrm{km}$ apart during one flight, and to perform horizontal scan at a given altitude along tens of $\mathrm{km}$.

[11] Fourteen flights were performed under 3 different geophysical conditions over the 2008-2010 period; Table 1 provides the conditions of the measurements. Two flights were conducted in June 2008 from Teresina, Brazil $\left(5^{\circ} 03^{\prime} \mathrm{S}\right.$, $\left.42^{\circ} 49^{\prime} \mathrm{W}\right)$ during dry season; 8 flights were conducted in August-September 2009 from Kiruna/Esrange $\left(67^{\circ} 53^{\prime} \mathrm{N}\right.$, $21^{\circ} 04^{\prime} \mathrm{E}$ ), Sweden, and 4 flights from Kiruna/Esrange in April-May 2010. Due to technical reasons, only measurements obtained during the descent were available for the 25 April 2010 flight. STAC was onboard the SPIRALE gondola on 9-10 June 2008 (Teresina) and on 7 and 24 August 2009 (Kiruna).

[12] The measurements are available from the middle troposphere up to the $14-2 \mathrm{hPa}(29-42 \mathrm{~km})$ altitude range depending on the size of the balloon. Flights were performed at various times of the day. In particular, the $7-$ 8 September 2009 flight was conducted from sunset to sunrise; the float altitude level of the balloon decreased from 7 to $14 \mathrm{hPa}$ during sunset, and increased from 14 to $9 \mathrm{hPa}$ during sunrise, allowing us to obtain two additional small vertical scans of the middle stratosphere.

\section{Aerosol Content in the Middle Stratosphere}

[13] Figures 1 and 2 present examples of size class vertical profiles obtained with STAC, on 19-20 June 2008 above Teresina (Brazil) and on 9 April 2010 above Kiruna

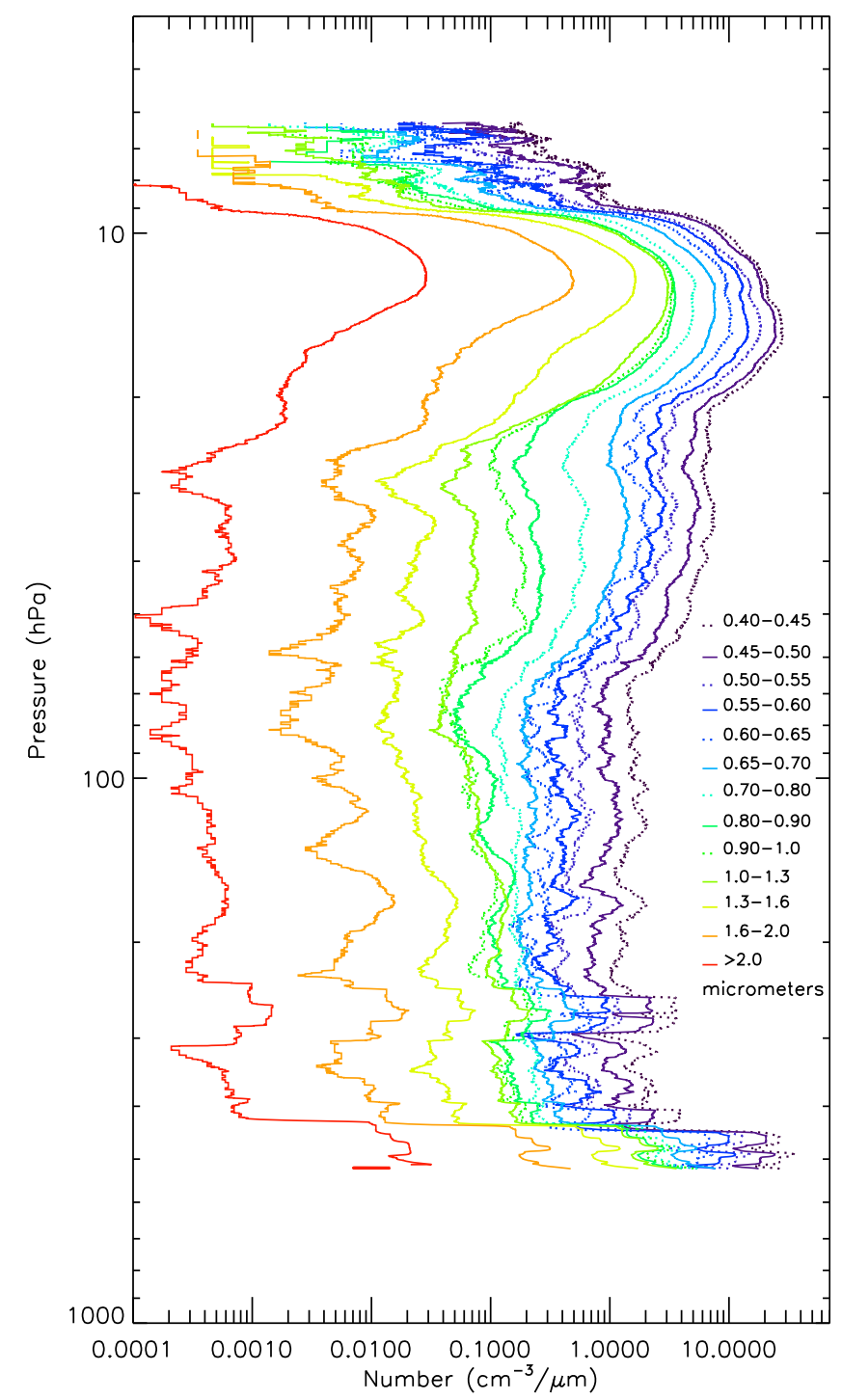

Figure 1. Aerosols size distribution above Teresina (Brazil) on 19-20 June 2008, assuming liquid aerosols. 


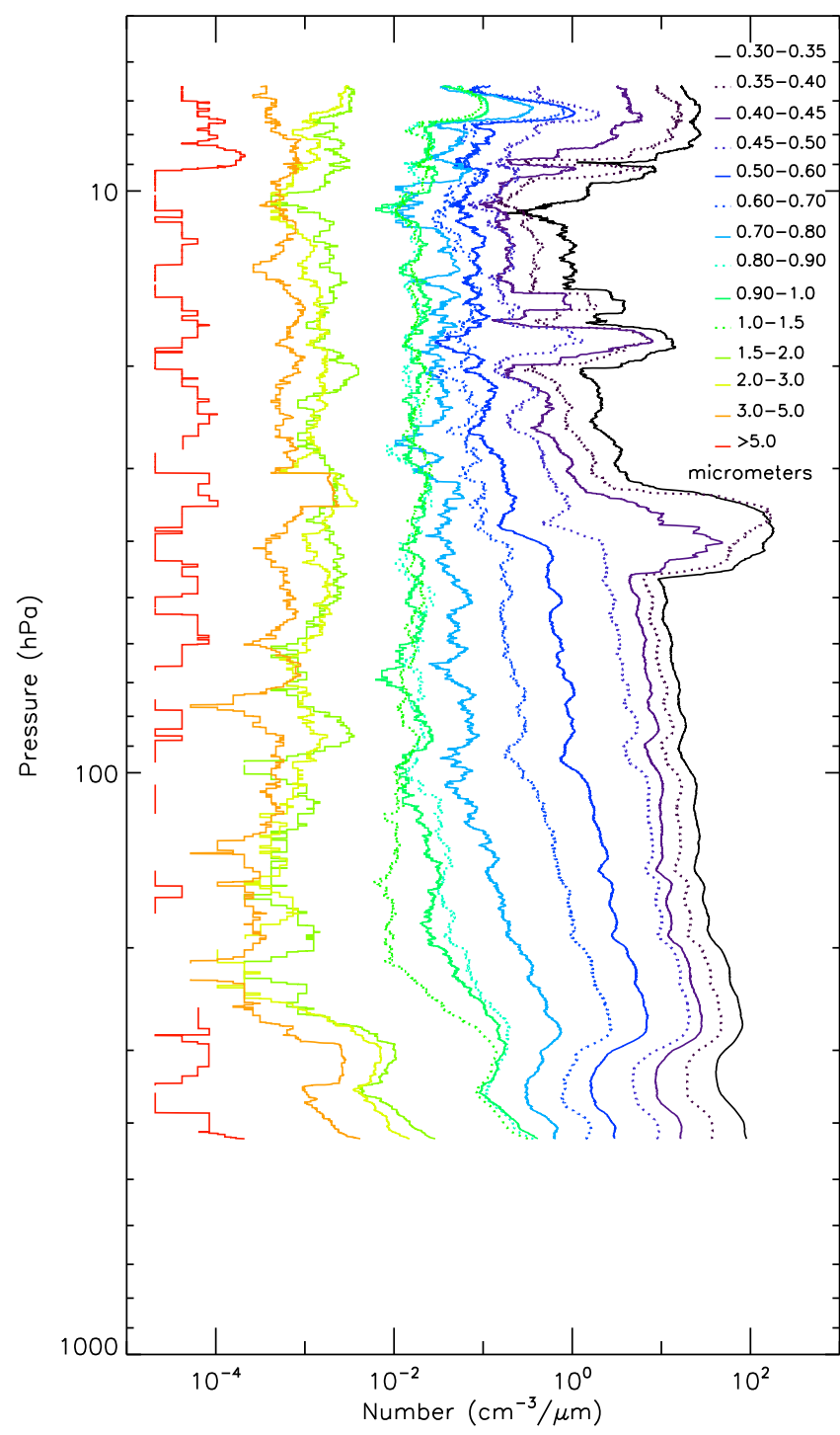

Figure 2. Aerosols size distribution above Kiruna (Sweden) on 9 April 2010, assuming liquid aerosols.

(Sweden). The profiles are presented in size distribution units, assuming liquid aerosols in the STAC calibration process. On the first profile (Figure 1), the main structure is a strong enhancement for all size classes between 20 and $10 \mathrm{hPa}$. A similar enhancement was also observed above Kiruna on 14 August 2009 between 12 and $7 \mathrm{hPa}$. On the second profile (Figure 2), several enhancements are detected only for the smallest size classes and for altitudes higher than $50 \mathrm{hPa}$. These layers have a vertical extent varying from a few hundred meters to less than $2 \mathrm{~km}$.

[14] These thinner layers are observed for most of the STAC flights where no strong enhancement is present. Sometimes these layers are detected at the same altitudes, both during ascent and descent several tens of kms apart, sometimes only during the ascent or the descent. Also, these layers were detected during cruise at constant float altitude for 4 of the flights (2 August 2009, 24-25 August 2009, 7 8 September 2009, 4 April 2010). From these observations, the horizontal extent of the layers can be estimated as sev- eral tens to few hundreds of $\mathrm{km}$. Such layers were identified during all the flights, indicating that the probability of their occurrence is high.

[15] The reality of such detection must be discussed. The enhancements were detected although STAC was onboard different gondolas with different shapes and materials used in their structures. The enhancements were observed for all the conditions of measurements (ascent and descent). Also, the thinner layers are often spotted at the same altitude during ascent and descent. These facts seem to rule out the possibility of contamination by the gondolas or by the balloons. Since the enhancements are not present for all the size classes in most of the cases, they cannot result from a bias induced by the pumping system.

[16] In Figure 3, the total concentration profiles of aerosols having diameters greater than $0.4 \mu \mathrm{m}$ (assuming liquid aerosols) are plotted for the 3 different geophysical conditions. Measurements of aerosols having diameters greater than $0.3 \mu \mathrm{m}$ are also available for the Kiruna 2010 observations and are also plotted in Figure 3 in order to evaluate the effect of the smallest aerosols contribution on the profiles. In the upper troposphere/lower stratosphere (300 $40 \mathrm{hPa}$ ), the aerosol content can change from one period to another, probably due to the atmospheric general circulation and to the seasonal variations of the regional conditions (such as atmospheric cleaning after the wet tropical season, if we compare Teresina and Kiruna profiles). On the other hand, these contents are stable all over a given campaign of measurements (from 3 to 5 weeks). In the middle stratosphere for altitudes above $40 \mathrm{hPa}$, the aerosol content is progressively more variable, with a stronger variability above $20 \mathrm{hPa}(27 \mathrm{~km})$ from one flight to another, or even during the same flight. The variability is even stronger when considering only the smallest particles. Thus, from these observations, there is some evidence about the presence of a non-homogenous aerosol layer in the middle stratosphere typically above $20 \mathrm{hPa}$. The upper altitude level of this layer cannot be determined due to the altitude limitation of the balloons, but seems to be located above $2 \mathrm{hPa}$.

\section{Nature and Origin of the Layers}

[17] The new detection of these layers above $30 \mathrm{~km}$ confirms the previous detection of aerosol optical thickness enhancements in the middle stratosphere performed by the UV-visible balloon-borne spectrometer SALOMON [Renard et al., 2008]. Nevertheless, to our knowledge, these enhancements have not been reported so far from the numerous measurements obtained by the University of Wyoming aerosol counter at various latitudes [e.g., Deshler et al., 2003]. This could be due to the fact that most of the flights were conducted with smaller balloons reaching lower altitudes. Also, such enhancements may not be detectable when large amounts of volcanic aerosols are present as it was the case after the Mt Saint-Helens and Mt Pinatubo eruptions.

[18] The two strong enhancements observed around $10 \mathrm{hPa}$ on 19 June 2008 (Figure 1) and 14 August 2009 (not shown separately from Figure 3) strongly differ from the other ones, both by their larger vertical extent (few $\mathrm{km}$ ) and size distribution (the largest size class concentration also increases). One of the best explanations could be the fortuitous detection of debris from meteoric disintegration, such as the one 

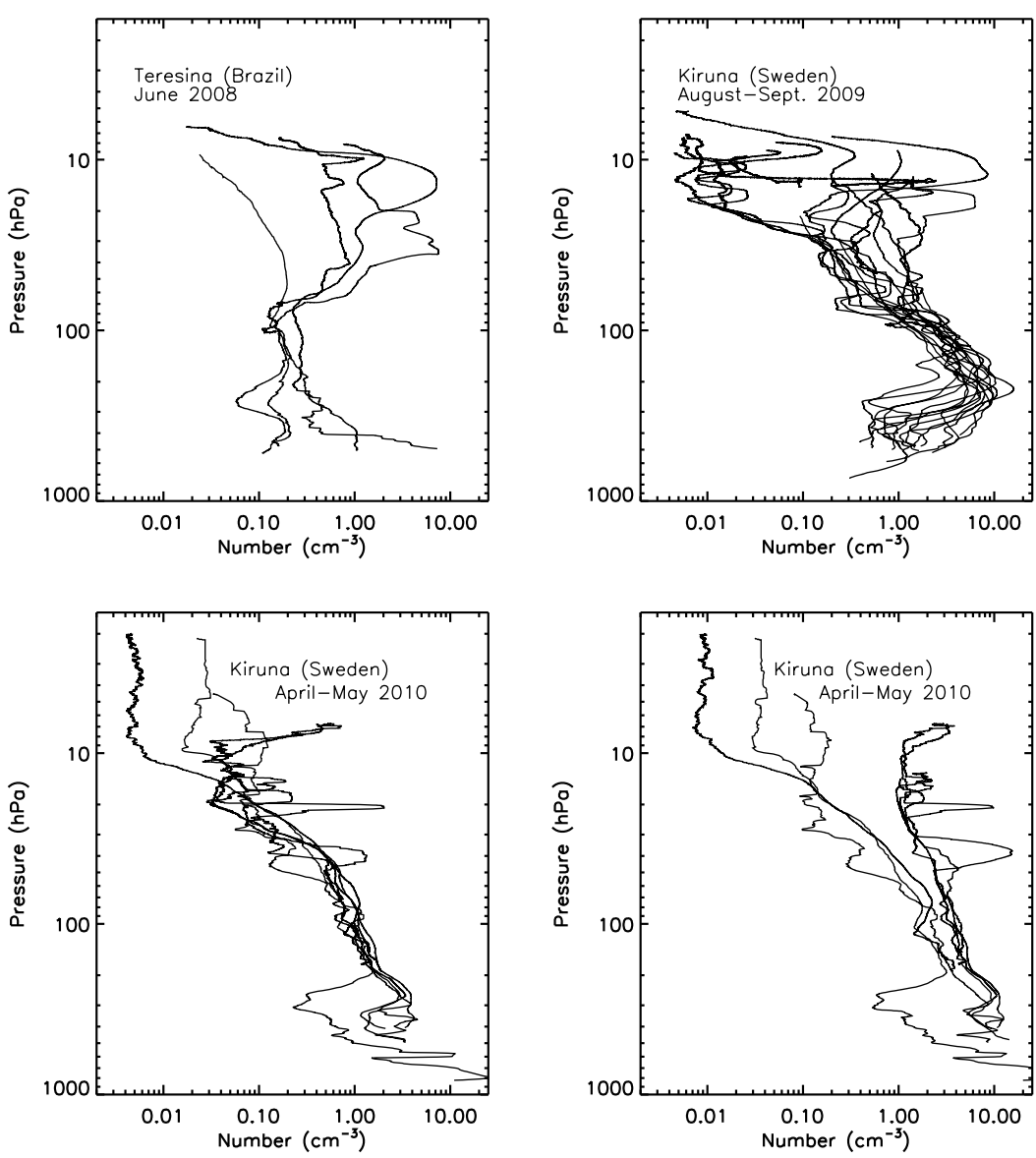

Figure 3. Concentration of aerosols (assuming liquid aerosols) observed under 3 different geophysical conditions described in Table 1; $(\mathrm{a}-\mathrm{c})$ aerosols with diameters greater than $0.4 \mu \mathrm{m}$; (d) aerosols with diameters greater than $0.3 \mu \mathrm{m}$ in the same geophysical condition as for Figure $3 \mathrm{c}$.

detected by Klekociuk et al. [2005] in 2004 (it could be noticed that the 14 August flight was performed during the perseids shooting stars period).

[19] The other enhancements (e.g., those on Figure 2) are characterized by strong vertical/horizontal gradients in concentration, corresponding to aerosol content increases over less than one hundred meters. This behaviour cannot be obtained for measurements conducted in mixed air, so the origin of the air masses must be analyzed. This can be done using the in situ SPIRALE infra-red spectrometer which performed high-vertical-resolution measurements of the $\mathrm{CH}_{4}$ and $\mathrm{N}_{2} \mathrm{O}$ tracers. Different source regions for the observed air masses would be characterized by increases or depletions in the vertical profiles of these species. Figure 4 presents an example of $\mathrm{N}_{2} \mathrm{O}$ measurements and aerosol content on 24 August 2009. There is no obvious correlation between the aerosols enhancements and the structures in the $\mathrm{N}_{2} \mathrm{O}$ profile. The same conclusion is obtained for $\mathrm{CH}_{4}$ during this flight, as well as for the other SPIRALE flights. Also, no correlation was found between the aerosol profile in the middle stratosphere and the in situ temperature and wind directions profiles measured during the flights. Finally, no direct connection with potential vorticity fields is noticeable at these altitude levels. Thus it seems that these aerosol enhancements are not directly related to the origins of air masses or to their transport by atmospheric general circulation.
[20] Another process must be investigated to tentatively explain the shape and the occurrence of these thin aerosol layers. The nature of these aerosols is unknown since STAC cannot allow us to distinguish between solid and liquid particles. At such high altitudes, it can be reasonably

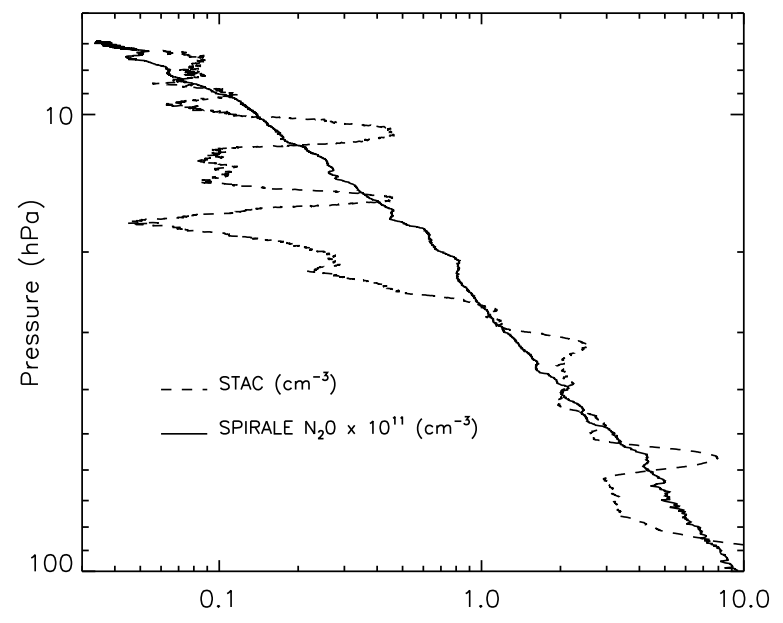

Figure 4. Comparison between STAC measurements of aerosols having diameter greater than $0.4 \mu \mathrm{m}$ (assuming liquid aerosols) and SPIRALE in situ measurements of N2O, on 24 August 2009 above Kiruna. 
assumed that aerosols are not liquid, thus soot and/or small meteoritic debris are the best candidates, following the results of Renard et al. [2008]. The sharpness of these features and the absence of correlation with the origin of the air masses lead us to assume that an additional element must be taken into account in order to separate their dynamics from that of these air masses. It could be proposed that such grains are electrically charged, as for "smoke" aerosols in the mesosphere [Amyx et al., 2008; Rapp, 2009] resulting from recondensation of vaporized meteorites during their atmospheric entry. In this case, local variations of atmospheric electric field might participate in the containment of aerosols depending on their charges.

\section{Conclusions and Perspectives}

[21] Unexpected (transient) aerosol layers were detected in the middle stratosphere. The nature and origin of these aerosols (meteoric debris, soot, ...), and the main process that leads to their containment, must be determined. Such studies cannot be conducted using conventional aerosol counters, thus new strategies of measurements are needed. The determination of the aerosol natures can be performed using the remote sensing balloon-borne radiometer MicroRADIBAL [Brogniez et al., 2003], which measures the aerosol scattered light (brightness and polarisation). A new flight is expected in 2011 with a float altitude around $35 \mathrm{~km}$. Also, STAC will be modified to detect the presence of charged aerosols, to validate or invalidate our hypothesis about the role of electric fields in the aerosol containment. Finally, a new climatology of middle and upper stratospheric aerosols, from GOMOS/ Envisat measurements of aerosol extinction, will soon be available to better quantify the occurrence and the vertical extent of the aerosol enhancements.

[22] Acknowledgments. The flights of STAC were performed during the FP7-European Integrated Project SCOUT-O3 (505390-GOCE-CT2004), the Envisat validation project funded by ESA and CNES, the STRAPOLETE project funded by French "Agence Nationale de la Recherche" and coordinated by N. Huret-Brun (LPC2E), and the AEROWAV project funded by CNES. The authors thank C. Camy-Peyret (LPMAA) and C. Brogniez (LOA), PI of some of the gondolas on which STAC was mounted, and the CNES balloon launching team for the flights often performed during difficult meteorological conditions. The data are available on the ETHER web site (funded by CNES and CNRS-INSU) at: http:// ether.ipsl.jussieu.fr.

\section{References}

Amyx, K., et al. (2008), In-situ measurement of smoke particles in the wintertime polar mesosphere between 80 and $85 \mathrm{~km}$ altitude, J. Atmos. Sol. Terr. Phys., 70(1), 61-70, doi:10.1016/j.jastp.2007.09.013.
Bingen, C., D. Fussen, and F. Vanhellemont (2003), Characterization of stratospheric aerosol distribution: Evolution of volcanic and non volcanic aerosol components observed through 16 years of SAGE II data 1984 2000, in Volcanism and the Earth's Atmosphere, Geophys. Monogr. Ser., vol. 139, edited by A. Robock and C. Oppenheimer, pp. 93-105, AGU, Washington, D. C.

Brogniez, C., N. Huret, S. Eckermann, E. D. Rivière, M. Pirre, M. Herman, J.-Y. Balois, C. Verwaerde, N. Larsen, and B. Knudsen (2003), Polar stratospheric cloud microphysical properties measured by the microRADIBAL instrument on 25 January 2000 above Esrange and modeling interpretation, J. Geophys. Res., 108(D6), 8332, doi:10.1029/ 2001JD001017.

Deshler, T., M. E. Hervig, D. J. Hofmann, J. M. Rosen, and J. B. Liley (2003), Thirty years of in situ stratospheric aerosol size distribution measurements from Laramie, Wyoming $\left(41^{\circ} \mathrm{N}\right)$, using balloon-borne instruments, J. Geophys. Res., 108(D5), 4167, doi:10.1029/2002JD002514.

Fussen, D., F. Vanhellemont, and C. Bingen (2001), Evidence of transport, sedimentation and coagulation mechanisms in the relaxation of postvolcanic stratospheric aerosols, Ann. Geophys., 19, 1157-1162, doi:10.5194/angeo-19-1157-2001.

Hervig, M. E., L. L. Gordley, L. E. Deaver, D. E. Siskind, M. H. Stevens, J. M. Russell III, S. M. Bailey, L. Megner, and C. G. Bardeen (2009), First satellite observations of meteoric smoke in the middle atmosphere, Geophys. Res. Lett., 36, L18805, doi:10.1029/2009GL039737.

Hitchman, M. H., M. McKay, and C. R. Trepte (1994), A climatology of stratospheric aerosol, J. Geophys. Res., 99, 20,689-20,700, doi:10.1029/94JD01525.

Hofmann, D., J. Barnes, M. O’Neill, M. Trudeau, and R. Neely (2009), Increase in background stratospheric aerosol observed with lidar at Mauna Loa Observatory and Boulder, Colorado, Geophys. Res. Lett., 36, L15808, doi:10.1029/2009GL039008.

Klekociuk, A., et al. (2005), Meteoritic dust from the atmospheric disintegration of a large meteoroid, Nature, 436, 1132-1135, doi:10.1038/ nature03881.

Lary, D. J., D. E. Shallcross, and R. Toumo (1999), Carbonaceous aerosols and their potential role in atmospheric chemistry, J. Geophys. Res., 104, 15,929-15,940, doi:10.1029/1998JD100091.

Moreau, G., et al. (2005), A multi-species in situ balloon-borne instrument with six diode laser spectrometers, Appl. Opt., 44(28), 5972-5989, doi:10.1364/AO.44.005972.

Ovarlez, J., and H. Ovarlez (1995), Water vapour and aerosol measurements during SESAME, and the observation of low water vapour content layers, in Polar Stratospheric Ozone: Proceedings of the Third European Workshop, Air Pollut. Rep. 56, edited by J. A. Pyle, N. R. P. Harris, and G. T. Amanatidis, pp. 205-208, Eur. Comm., Paris.

Rapp, M. (2009), Charging of mesospheric aerosols particles: The role of photodetachment and photoionization from meteoric smoke and ice particles, Ann. Geophys., 27, 2417-2422, doi:10.5194/angeo-27-2417-2009.

Renard, J.-P., et al. (2005), Optical and physical properties of stratospheric aerosols from balloon measurements in the visible and near-infrared domains. III. Presence of aerosols in the middle stratosphere, Appl. Opt., 44(19), 4086-4095, doi:10.1364/AO.44.004086.

Renard, J.-B., et al. (2008), Vertical distribution of the different types of aerosols in the stratosphere, Detection of solid particles and analysis of their spatial variability, J. Geophys. Res., 113, D21303, doi:10.1029/ 2008JD010150.

Solomon, S. (1999), Stratospheric ozone depletion: A review of concepts and history, Rev. Geophys., 37, 275-316, doi:10.1029/1999RG900008.

G. Berthet, V. Catoire, B. Gaubicher, J.-B. Renard, C. Robert, V. Salazar, and M. Tagger, LPC2E, Université d'Orléans, CNRS, $3 \mathrm{~A}$ avenue de la recherche scientifique, F-45071 Orléans CEDEX 2, France. (jbrenard@ cnrs-orleans.fr) 